Revista Iberoamericana. Vol. LXIII, Núms. 178-179, Enero-Junio 1997; 209-218

\title{
LA ESFERICIDAD DEL PAPEL: \\ GERTRUDIS GÓMEZ DE AVELLANEDA, LA CONDESA DE MERLIN, Y LA LITERATURA DE VIAJES
}

\author{
POR \\ RAÚl IANES \\ Miami University, Oxford-Ohio
}

\begin{abstract}
Uno de tantos libros curiosos como circulan por esos mundos y gracias a los cuales alcanzamos todos la ventaja inestimable de viajar sin movernos de nuestro sitio.
\end{abstract}

Gertrudis Gómez de Avellaneda, Espatolino.

La que suele entenderse como literatura de viajes no es generalmente asociada con la obra de Gertrudis Gómez de Avellaneda (1814-1873). Tradicionalmente —y con sobrado criterio- los cánones fundamentales que señalan y delimitan la presencia de la autora cubana en las historias literarias y el trabajo de la crítica son sus composiciones líricas, sus dramas históricos y en época reciente una vigorosa si bien parcial revaluación de su obra narrativa.

Este trabajo aspira a detenerse en aquellos aspectos de la obra de la Avellaneda que en mayor o menor medida claramente revelan como intertexto la presencia de la literatura de viajes. Y en ese sentido no sólo como género narrativo que corresponde a una de las prácticas sociales y culturales de su época, sino también, como ámbito discursivo en el que se articula la heterogeneidad y la totalidad textual que enmarcan y definen su obra a partir de sus específicas circunstancias históricas y culturales.

En 1839, al firmar sus primeras colaboraciones para La Aureola de Cádiz como La Peregrina (Cotarelo y Mari 195), la Avellaneda, —no hacía mucho llegada a España desde su nativa isla y casi una desconocida en la Península - ideaba una rúbrica literaria que, si bien por un lado no postulaba original singularidad, por el otro clara e intencionalmente apuntaba - junto a otras claras resonancias del término- a la personalidad concreta de la autora antillana. Se puede concluir que en esa dimensión significativa particular, es decir, las circunstancias concretas de su enunciación, el seudónimo inicial expresa y compendia una subjetividad expresaday leíble en términos de distante origen geográficoy, consecuentemente, probable procedencia desde un específico, remoto y por lo tanto diferente ámbito natural y cultural. ${ }^{1}$

\footnotetext{
${ }^{1}$ Mary Cruz anota que el seudónimo La Peregrina fue escogido por el director del periódico gaditano, su amigo Manuel Cañete, de entre más de uno propuesto por la autora cubana ("Prólogo", Obra selecta xi). No deja de ser significativo y digno de atención que la Avellaneda comparta el calificativo con su isla nativa. Mary Cruz destaca la inclusión en las Obras literarias de 1869 - habiendo ya estalladado en Cuba la Guerra de los Diez Años- del poema "A S.M. la reina doña Isabel II", originalmente
} 
Nótese además que, en cuanto a su poder referencial, el seudónimo de 1839, más que encubrir una identidad - después de todo esperado propósito de un nom de plume - debe ser leído aquí como una aspiración a las dimensiones de un epíteto. El camino hacia el referente concreto que claramente está señalando — en este caso la identidad de la autora - está firmemente sugerido a través de una significación selectiva y de la connotación que en su contexto enunciativo adquiere el término escogido. En otras palabras, la firma literaria de los comienzos de la Avellaneda ostenta emblemáticamente una cualidad vital concreta, y remite, por medio de su clara carga semántica, al dato biográfico identificador (e identificable) de la escritora. De ahí que también corresponda interpretarlo en el sentido que probablemente la firma adquiriera para el lector de su época y de su ámbito literario, recordando de paso que en este caso muy probablemente deba asumirse como "lector" a un reducido grupo de colegas escritores y/o suscriptores interesados en las bellas letras. Dentro de esos parámetros, por lo tanto, debe interpretarse también en el sentido que, si bien no exactamente una extranjera en la Península, a la autora de las composiciones gaditanas la distingue, de cara a su público, un lejano, periférico, y tal vez exótico origen. Insistiendo en esa hermenéutica, o demorándose en circunscribir y limitar esas siempre imprecisas categorías a un concreto paradigma tanto histórico como lingüistico y geográfico, se puede entonces culminar por leer, en la rúbrica de 1839 , lo que probablemente constituye su verdadera intención significativa: la autora ostenta un origen colonial, de española ultramarina.

La carrera literaria de la Avellaneda se inaugura, por lo tanto, con una autocalificación de significancia ambivalente que decididamente señala la procedencia desde uno de los márgenes del espacio cultural que comparte con su audiencia, y concurrentemente, una manifiesta (auto)diferenciación no exenta de notable narcisismo personal y nacional, si es que en su caso - como en todo autor romántico - se pudiese llegar a un deslinde de ambos. Pero tal comoHomi Bhabha ha señalado "cultural difference must not be understood as the free play of polarities and pluralities in the homogeneous empty time of the national community [...] Cultural difference, as a form of intervention, participates in a logic of supplementary subversion similar to the strategies of minority discourse"(162), siendo que el propósito de la diferenciación cultural en un topos de enunciación determinado "is to rearticulate the sum of knowledge from the perspective of the signifying position of the minority that resists totalization" (Bhabha 162). Dadas esas pautas, la rúbrica inicial de la Avellaneda temprana intencionalmente establece, desde el nuevo centro de enunciación, lo que será un rasgo biográfico básico y fundamentalmente idiosincrático de su personalidad literaria y su escritura: una definición cultural esencialmente intersticial y por ende perturbadoramente integradora de la conflictiva dicotomía colonia-metrópoli, isla-continente, América-Europa, propia de las circunstacias históricas y personales que le toca vivir.

Desde otra perspectiva obsérvese que, al mismo tiempo, la firma-epíteto de 1839 no deja de estar fuertemente connotada en términos de historia literaria o, más exactamente, en la dimensión diacrónica de la tradición narrativa. Desde esa perspectiva no debe asumirse que

compuesto con motivo de la declaración de la mayoría de edad de la soberana española en 1843 y en el que la Avellaneda se refiere a Cuba en los siguientes términos: "la perla más valiosa y peregrina / que allá, olvidada en su distante zona / do libre ambiente a respirar no alcanza / con ansia aguarda que la lleve el viento / — de nuestro aplauso en el gozoso acento- / la que hoy nos luce espléndida esperanza" ("Prólogo" xxi. El texto íntegro del poema puede consultarse en Obras I, 285-86). 
el seudónimo de La Aureola deba resultar inocentemente vacuo, literariamente neutro, sino precisamente todo lo contrario. En él puede leerse el reclamo de todas las narrativas que desde las más remotas y antiguas fuentes se estructuran, repiten y amplifican en torno al topos del viajero; léase, por metonimia, la referencia a la ficción de todas las épocas y culturas. En The Secular Scripture, al abordar el estudio del romance como forma seminal de todo relato de ficción, Northrop Frye privilegia, trayéndola a colación, la alegoría borgeana que sintetiza esa continuidad genérica en las siguientes palabras: "a lo largo del tiempo [los hombres] han repetido siempre dos historias: la de un bajel perdido que busca por los mares mediterráneos una isla querida, y la de un dios que se hace crucificar en el Gólgota" (15). ${ }^{2}$

Dados estos antecedentes de la Avellaneda, es decir, por un lado su traslado geográfico entre colonia y metrópoli como crucial instancia biográfico-cultural y por otro la consabida posibilidad de referirse a toda literatura de ficción como metáforas de periplos viajeros por multiplicidad de mundos imaginativos, no debería sorprender la frecuente aparición del topos del viaje y el viajero en los distintos géneros literarios cultivados por la autora cubana. En primera instancia y fundamentalmente relacionada a la dimensión autobiográfica, la temática del traslado geográfico parecería no requerir mayor explicación que esas premisas previas. Recuérdese el motivo del viaje - concretamente el del cruce oceánico-en algunas de sus más célebres y recordadas composiciones poéticas, como pueden ser "Al partir," escrito en 1836 al dejar Cuba por primera vez a bordo de la fragata Le Bellochan y "La vuelta a la patria", sin dejar de lado otras como "El viajero americano" en la que Mary Louise Pratt sagazmente señala una paródica reelaboración de esa "Humboldtian fascination with volcanos and the forces of volcanic energy" transparentemente inspirada en el viaje de treinta tomos del sabio alemán (Pratt 194). De manera paralela, otras poesías líricas de la Avellaneda como pueden ser "A vista del Niágara", "Paisaje guipuzcoano" o los protomodernistas versos de "Los reales sitios" agregan, en mayor o menor grado, una significativa variante a la temática del viaje como simple desplazamiento espacial, haciendo referencia o claramente presentando el motivo literario de la gira, la visita a sitios seleccionados o la excursión "turística" que está en boga en la Europa de su tiempo. Éstos son recorridos sin otro fin aparente que el recreo personal, la visita a determinados lugares para conocer su singular belleza natural o bien detalles de importancia histórica y cultural y que por último, representan el deleite en el viaje como motivo de lo lírico-poético. En general, y como correlato escrito de una actividad social y cultural, el relato del viaje de turismo presenta en el siglo diecinueve una serie limitada de loci privilegiados por los tradicionales tours americanos y europeos de mediados del siglo pasado. Es así como en esas composiciones de la Avellaneda abundan las notas con el propósito de ampliar la información sobre el recorrido poetizado, a la manera de: "Esta composición fue hecha por la autora yendo a visitar, a pie, con su marido, la ermita de Nuestra Señora de la Esperanza, en Ubarri, desde los baños de Santa Agueda". ("Paisaje guipuzcoano" Obras I, $334, \mathrm{n} 34$ ) o el dato físico concreto que revela en la poeta cubana, una vez más, el interés por el detalle físico-natural y su minucioso registro textual: "Se calcula en noventa millones de toneladas las aguas que arrojan cada hora las cataratas del Niágara, las cuales sirven de escape, digámoslo así, a una inundación que cubre 150.000 millas cuadradas" ("A vista del Niágara" Obras I, 351, n. 44).

\footnotetext{
${ }^{2}$ La cita de Borges proviene de "El evangelio según Marcos".
} 
No obstante, esta breve consideración de algunos fragmentos literarios y notas delata ya de por sí una cierta complejidad textual, una intersección de múltiples planos de significación cuyos referentes se relacionan a la obra de la autora cubana obedeciendo a diferentes prácticas discursivas, las que no son sino a su vez la proyección textual de esa hibridezy diferenciación cultural de la autora en el medio que corresponde a su enunciación literaria y a la que volveremos más adelante. Lo que tal vez podría llamar la atención en el caso de la Avellaneda - si es que se tienen presentes sus desplazamientos geográficos, su interés en la paisajística y su gusto por el turismo- sumado a la época en la que escribe, en la que "el turismo es ya una pasión" (Sebold 57), es el carácter marginal, aparentemente tangencial o tal vez difusamente sincrético que el motivo del viaje ocupa en su producción literaria. En otras palabras, la ausencia, al menos bajo una forma textual autónoma y genéricamente discreta, del relato de viajes extenso, de tan amplia composición y popular lectura en la literatura del siglo pasado. Eso no quiere decir, claro está, que la literatura adscribible a ese género esté totalmente ausente de su producción. En ese sentido se puede seguramente considerar tanto relato autobiográfico como de viajes los cuatro cuadernillos de 1838 concebidos como epístola a su prima Eloísa de Arteaga que describen su salida de Cuba y sus primeros meses de estancia en Europa, período en el que visita parte de Francia y algunas regiones españolas. A esa categoría tal vez se aproxime más aún su relato "Mi última excursión por los Pirineos", aparecida en sucesivas entregas como folletín del Diario de la Marina de La Habana en 1860 y recogida posteriormente en la edición del centenario de 1914. "Mi última excursión" es un texto que pormomentos se aproxima a lo que podría ser calificado como una guía para viajeros. A ambos lados de los Pirineos, la autora se complace en detallar no solamente ciudades, recorridos, monumentos y lugares que guardan historia, sino que también se permite agregar —a la manera de experimentada turista buena conocedora de la región- datos prácticos y recomendaciones sobre hotelería, comodidades disponiblesy hasta el precio de los alojamientos, al tiempo que incorpora términos de la jerga turística europea, tales como tourista, cicerone, confort. Veamos, según "Mi última excursión", las condiciones que ofrece al viajero la hotelería en la ciudad francesa de Pau:

Varios son los hoteles en que puede hospedarse perfectamente el forastero, y entre los que se distinguen el de Francia, el de la Posta y el de Europa, cuyos dueños son españoles; mas las familias que permanecen largas temporadas toman por lo común habitaciones amuebladas (appartements garnis) teniendo muchas para escoger y a precios nada exagerados. Nosotros vimos una lindísima casa, en situación admirable y decorada con magnificencia, por la cual nos pidieron tres mil francos anuales (menos de seicientos pesos). Otras muy confortables, pero más pequeñas, no exceden de mil quinientos a dos mil francos (19).

Pero bajo el aspecto del relato de una excursión veraniega, "Miúltima excursión" - texto que en su carta al Director del Diario de la Marina la autora no vacila en reiteradamente denominar como "ligeros apuntes", "notas", o "borradores"- obedece primordialmente, según su declarado y anotado criterio, al fallido propósito de narrar las "tradiciones literarias que poetizan" los lugares visitados:

Mi primera intención de fundar sobre aquellas notas un extenso y agradable relato de mi última correría, realzando cuanto pudiera el interés de las tradiciones (recogidas en un país 
en el que son tan abundantes), me pareció imposible después de haberse borrado de mi mente multitud de datos con que contaba para auxiliar los consignados en el papel, que eran por desgracia los menos (47).

El propósito claramente literario de "realzar el interés de las tradiciones" lo lleva a cabo la autora incorporando al texto de "Mi última excursión" dos de ellas: "Los doce jabalíes" (o "Leyenda de Avendaño y Elvira") y "La ondina del lago azul" que aparecerían luego separadamente y agrupadas con sus otras leyendas en sus Obras completas de 1869. Pero asimismo, "Mi última excursión", y tal como la autora se ha preocupado en dejar en claro, obedece a un propósito claramente literario asociado con el recorrido turístico. La visita a abadías, sitios históricos y la búsqueda de las antiguas tradiciones en el recorrido del viajero aparecen también, aproximadamente en la misma época, en las leyendas de Bécquer. ${ }^{3}$ Es así que la excursión pirenaica de la Avellaneda presenta conjuntamente con el dato turístico concreto, aspectos de relato de ficción, incorporando las ya citadas leyendas, el relato de Mme. deCottin y el sugestivoy misterioso episodio de los tres enigmáticos ingleses que distantemente siguen al grupo de excursionistas.

Lo que podríamos denominar "literaturización" del recorrido viajero tiene su correlato opuesto, en la narrativa de ficción de la Avellaneda, en la presencia casi constante del motivo del viaje en sus leyendas y novelas. Es así como en Espatolino (1844), que abre su acción en Italia, la autora dedica el párrafo inicial a plantear el recorrido turístico - real o librescocomo elemento decisivo para la ambientación y la lectura de su novela:

\begin{abstract}
¿Habéis estado alguna vez en Italia? Si por pereza o absoluta carencia de medios no habéis tenido aún la dicha de recorrer aquella privilegiada región de Europa, no os habrá faltado, por lo menos, uno de tantos libros curiosos como circulan por esos mundos, y gracias a los cuales alcanzamos todos la ventaja inestimable de viajar sin movernos de nuestro sitio [...] ¿Y quién además, no ha tenido a mano una de aquellas innumerables guías con cuyo auxilio se logra en pocos minutos conocer palmo a palmo aquella tierra bendita, inexhausta fuente de inspiración para el poeta y el novelista? Dando, pues, por indudable que conocéis - tanto como yo misma al menos - la parte del mundo a que intento transportaros, espero me seguiréis sin ningún género de temor o desconfianza, $\mathrm{y}$ aún supongo que no me impondréis en toda su extensión la enojosa tarea de cicerone (11).
\end{abstract}

Considérese también que bajo las características de la asociación metonímica con el relato de viajes un texto de la autora cubana próximo al recit de voyage es el prefacio biográfico que la Avellaneda escribió para la abreviada traducción española del Viaje a la Habana de su compatriota Mercedes de Santa Cruz y Montalvo, condesa de Merlin, originalmente escrito en francés y que en 1844 apareció en la Revista de Madrid. ${ }^{4}$

Al mencionar el Viaje a La Habana desde una perspectiva crítica centrada en su aspecto autobiográfico Sylvia Molloy señala el origen en gran medida libresco y ficticio del relato de

\footnotetext{
${ }^{3}$ De acuerdo con Sebold "se trata de reflejos literarios de una actividad turística que el mismo Bécquer había esperado popularizar entre los burgueses por medio de su Historia de los templos de España (1857), aprovechando para ello la nueva boga turística a la par que antecedentes como el Viaje de España, de Antonio Ponz, de la centuria anterior" (58).

${ }^{4}$ La versión francesa original lleva por título La Havane (1844).
} 
la condesa franco-cubana: "Rediscovery came to her less from what she saw on that trip than from what she read, remembered and imagined"'(Molloy 93). Ausente de Cuba desde sus años de infancia, la composición del Viaje a La Habana de la condesa de Merlin queda en deuda con los relatos de viajeros (reales), las largas epístolas de sus amigos en la isla y los textos de los costumbristas cubanos de la época. No es casual que en La loma del ángel (1987) - una brillante reescritura paródica del canónico subtítulo de Villaverde- Reinaldo Arenas elija presentar a la condesa como exótico centro de atracción en el paseo de la sociedad habanera, de visita (en persona) en su isla nativa, sonriendo desde su carruaje sin mirar a nadie y con una exótica mona de Madagascar en la falda. Si la extravagante condesa de Arenas no parece especialmente interesada en la recolección de datos cubanos para su Viaje a la Habanatítulo que tampoco escapa a la parodia en otro texto de Arenas- su caricatura resulta una hiperbólica representación paródica de la viajera por antonomasia, a quien en este caso le basta que el viento del malecón habanero infle sus faldas para arribar volando de vuelta a Europa.

El libresco viaje de la condesa de Merlin al Nuevo Mundo merece ser mencionado aquí por dos aspectos. Por un lado, como acertadamente señala Molloy, la autora del Viaje a la Habana creará su relato a partir de la reescritura de otros, repitiendo la sempiterna fórmula borgeana de toda narrativa como una reescritura. Por otro, el admitir tal naturaleza del proceso de composición de un relato de viajes presupone una actividad previa a la escritura bajo la forma de un recorrido previo y una lectura selectiva de esos textos a partir del cual se origina el suyo. Se trata por lo tanto, de seleccionar referentes que crearán, en definitiva, la ilusión del viaje real, a partir de un conjunto de textos, un inventario o repositorio del referente americano. Es el viaje por (con)textos que similarmente caracterizará la narrativa americana de la Avellaneday que guarda obvia correspondencia con lo que Michel de Certeau denomina casos de "library navigation" (138). En su amplio estudio histórico de la relación entre la novela y el relato de viajes cita Percy Adams esos monumentales textos dieciochescos que deben su acopio de datos y sus amplios itinerarios a la lectura, a la manera de los doce tomos de la célebre Histoire générale des voyages del abate Prévost.

Pero volviendo a la relación entre texto autobiográfico y la narración de viajes, el considerar el primero nos permite acercarnos a los desplazamientos tanto reales como ficticios de la Avellaneda. Se podría decir que en simetría textual con el relato de la condesa, cuyo Viaje es, como hemos visto, un texto esencialmente autobiográfico, la serie de Autobiografias escritas por la Avellaneda - sin dejar fuera su nutrido epistolario - constituyen narrativas en las que quedan no solamente (con)fundidos los discursos de la autobiografia y el relato de viajes, sino que queda instituido un espacio semántico sobre el que se proyecta la imagen del Otro americano.

La primera de la serie de escritos autobiográficos, es, en orden de publicación, la última y ya la hemos mencionado; se editó póstumamente en La Habana para su centenario (1914) y lleva por título Memorias inéditas de la Avellaneda. En realidad se trata de una carta fechada en 1838 y dirigida a su primaEloísa de Arteaga y Loinaz. En la larga misiva Tula, como hemos visto, narra el primer viaje de Cuba a España, pasando antes por Francia. Al llegar a La Coruña, su puerto de entrada a la Península, las Memorias prosiguen relatando las excursiones por distintas localidades gallegas y posteriormente el traslado, vía marítima, a Andalucía. Se trata del primer encuentro de la viajera antillana con Europa, fuera de una breve recalada previa en Burdeos. Las Memorias poseen un tono costumbrista, y de las ciudades españolas, la viajera antillana prefiere, sintomáticamente, una de tradicional proyección atlántica: 
Las casas de Cádiz son, como las de Burdeos y la Coruña, todas de piedras y muy altas; pero ¡qué hermosas! Iguales y con lindas azoteas, cubiertas éstas de jarrones de porcelana con diversidad de flores, $\mathrm{y}$ los balcones y ventanas pintados de vivos colores, adornados también con macetas de flores, presentan una vista tan hermosa y alegre, que parece ríe la ciudad. Grande, magnífica es Lisboa; hermoso y animadísimo Burdeos; soberbia y bella Sevilla; pero ¿qué ciudad del mundo será tan seductora y risueña como Cádiz? (Cotarelo y Mori 27)

Cubana por nacimiento y en gran medida por identificación emocional —si bien ciudadana metropolitana por residencia y ámbito literario - no es de extrañar la frecuencia y el interés con que aparece el motivo del viaje como peculiar instancia biográfica en la obra de la Avellaneda. Las abundantes referencias a Cuba y lo cubano - y por metonimia a toda América y lo americano- pueden ser entendidas, trascendiendo la obvia dimensión autobiográfica, como elementos textuales que voluntariamente apuntan a definiry caracterizar la esencia de su persona colonial en la metrópolis. Coincidentemente, esa diferenciación en términos espacio-culturales delimita un territorio exótico donde se constituirá el repositorio de los motivos seleccionados del referente americano. En él tendrá también natural cabida su galería de personajes, poseedores de un paradigma de rasgos donde se refleja la narcisística imagen de la autora. Hacia el final de Guatimozín (1846), una doña Marina que es quizás más Gertrudis que Malinche - y que incluso posee la comparativa experiencia de lo noamericano- declara su amor a Cortés en los siguientes términos: "Os adoro cual nunca sabrán amar mujeres que no hayan nacido bajo el sol ecuatorial que alumbró mi cuna" (442).

De forma similar a la condesa de Merlin, la Avellaneda rescata ese referente recurriendo en parte a la memoria, pero en fundamental medida, y para volver a la metáfora de de Certeau, mediante una extensa y minuciosa "navegación de biblioteca".

En cuanto a la representación del motivo del viaje en las novelas de la Avellaneda, es decir, como episodios en la diégesis narrativa, sus dos títulos de tema americano, Sab (1841) y Guatimozín (1846), incluyen, en el conjunto de su diversidad textual,la instancia del récit de voyage. Es singular leer en el capítulo IX de $S a b$, no solamente la excursión que el grupo familiar, "llevando a Sab por cicerone" (97), realiza de las grutas de Cubitas, cavernas llenas de extrañas formaciones geológicas y sobre las paredes de las cuales dejan siempre su firma los visitantes, sino también, en estilo de guía turística, la descripción de las distintas salas a la que se agrega la recomendación de no pasarlas por alto en una visita la isla.

Guatimozín, por su parte, incluye un viaje que el futuro emperador hace a las provincias antes de aparecer en los registros históricos en que la novela se basa. En esa instancia el romance certifica el previo viaje metafórico de la autora por los textos-inventarios de la naturaleza americana. La crítica parece no haber reparado aún, hasta qué punto está presente en los textos de la Avellaneda la intersección de un registro discursivo cuyo modelo narrativo, como convincentemente ha sostenido González Echevarría, se encuentra en los relatos de viajeros y muy particularmente en los monumentales inventarios naturalistas de los exploradores europeos de los siglos XVIII y XIX (léanse, entre otros La Condamine, Ulloa, Mutis, Malaspina y la legión de británicos). Prolijas notas como la que sigue, acompañan en $S a b$ la visita de Carlota a lo que podríamos llamar una especie de jardín botánico privado, un hortus conclusus $^{5}$ donde su amante esclavo cultiva, para su solo deleite, ejemplares nacionales:

${ }^{5}$ Tomo prestado este concepto, en su aplicación a la literatura caribeña, de Ileana Rodríguez. 
Esta flor extraordinaria la produce una planta parecida a la vid silvestre blanca. Antes de abrirse es de color jacinto claro, y abierta descubre otras hojas más blancas formando un círculo que imita una corona. Del centro de la flor se eleva un tallo cilíndrico a manera de una columna que remata en una especie de cáliz, del cual nacen tres clavos. Presenta además lo interior del cáliz la figura de un martillo, y por todos estos signos se la llama flor de pasión o pasionaria (63).

Claro que al señalar este componente textual en la novela de la Avellaneda soy consciente de que no estoy identificando por primera vez tal variante discursiva. En un apartado de sus Ensayos que lleva precisamente por título "Las fórmulas del americanismo" Pedro Henríquez Ureña recordaba, tiempo atrás, que "de mucha olvidada literatura del siglo XIX sería justicia y deleite arrancar una vivaz colección de paisajes y miniaturas de flora y fauna"(43). Como certeramente explica Antonio Benítez Rojo, el cúmulo textual dejado en América por el humanismo jesuítico y las exploraciones científicas del siglo XVIII se constituyó en referente para el discurso totalizador y dialógico de la novela. El romanticismo no desmantela el mito neoclásico de la naturaleza, sino que lo vuelca en sus nuevos moldes y es así como se asiste, en el siglo XIX, a la sobreabundancia de motivos referentes a todas las categorías de la naturaleza americana, entre ellas la flora y fauna. La propiedad mimética del deseo explicaría aquí el haber hecho suyo el deseo del Otro al momento de nacionalizar el discurso literario en una de sus formas más patentes.

Si en más de una oportunidad la Avellaneda menciona a Sab como una "novelita", sintomáticamente iniciada durante su viaje a España de 1838 y escrita en "ratos de ocio", (Cotarelo y Mori 23) para Guatimozin, parece haber aspirado a la monumentalidad de las grandes novelas históricas a lo Scott que leía en su juventud y la composición de la novela histórica encarada con la más minuciosa y consciente disposición creadora. En una carta de 1844 a su amante García Tassara, la Avellaneda confiesa haberse "desvivido por hacer una novela digna de figurar al lado de las buena novelas históricas ... escrita con grande esmero [y para la cual] la autora ha hecho un estudio profundo de la historia de la conquista, [y] del estado de la civilización azteca" (Méndez Bejarano 42-43).

Guatimozín, último emperador de México, primeramente aparecida como folletín de $E l$ Heraldo de Madrid en 1846 es una de las primeras novelas históricas sobre la Conquista de México y, dentro de la narrativa de la Avellaneda el caso más obvio de "library navigation" es decir, un texto donde se inscriben, desde diversos ángulos, y enmarcadas en el monumentalismo de su reconstrucción histórica, las variantes discursivas anteriormente señaladas. Dadas las limitadas posibilidades ofrecidas para la originalidad de la fábula, Guatimozin se desplaza hacia lo que se podría considerar un texto (meta)historiográfico que permanentemente coteja las fuentesy al hacerlo revela la selectividad y el carácter fragmentario del discurso histórico, amén de las preferencias o recomendaciones contenidas en las disertaciones de la autora, muchas veces dirigidas a corregir lo que cree ser un error de información o interpretación de los hechos históricos. En la amplia posibilidad abierta por la forma narrativa que llamamos novela, que por definición y naturaleza genérica es una forma textual abierta a la inscripción de variados discursos y a la dimensión dialógica, la Avellaneda narra y documenta su extenso periplo por los espacios textuales de la historia, la geografía y la naturaleza americanas. Pero dado que Guatimozín es una novela histórica, obviamente debe 
ser considerada a la luz del historicismo que de acuerdo con Foucault se erige en disciplina estructuradora de la episteme decimonónica y consecuentemente de la aproximación textual entre historia y novela que caracteriza a la narrativa del siglo XIX, basada en una idéntica configuración de universos textuales. Como novela histórica del romanticismo hispanoamericano, Guatimozin participa del proceso de flexión y aclimatación de un género, de un "modelo oportuno" para citar los esclarecederos términos con que Noé Jitrik explica el complejo proceso discursivo de "operaciones de ordenamiento" y de estrategias textuales a través de las cuales se plantea en la narrativa hispanoamericana del siglo diecinueve un temprano y enérgico intento de "despertar nacional y cultural" (Jitrik 34-36). Tal como destaca Barthes, historia y novela decimonónicas se caracterizan por diseñar ambas, en el período de su mayor desarrollo, mundos narrativos que obedecen a las mismas pautas de construcción de sus dimensiones, límites, personajes y mitologías. Es así que ese "mundo novelístico", aparentando la negación del aspecto lingüístico y por ende significativo del texto narrativo, aspirará, igual que el discurso historiográfico, a fundamentarse en la técnica realista de l'effet du réel bartheano.

La Avellaneda parece haber intuido la importancia espacial de su itinerario textual, es decir, la necesidad de densificar ese espacio cultural a efectos de alcanzar la necesaria dimensión y densidad históricas, lo que Barthes denomina, salvando las distancias, "cette sphéricité des grandes œvreus du XIX siècle" (25). El concepto bakhtiniano del cronotopo nos recuerda, por otra parte, la inseparabilidad de tiempo y espacio. De la capacidad del autor para dar volumen a este último, dependerá, entonces, la posibilidad de corporizar el anterior. La técnica paratextual de las notas explicatorias registra el detallado itinerario mexicano de la autora a través de las crónicas e historias de López de Gómara, Bernal Díaz, Solís, Robertson, y Prescott entre otros. Los textos dieciochescos del jesuita Clavijero y los del sabio italiano Boturini Benaducci - con su rigor científico y su discurso interpretativo de la naturaleza cíclica de las sociedades humanas inspirado en Vico-se constituyen en el espacio-repositorio del referente americano donde la autora cubana cumple su erudito periplo de biblioteca para la composición de su novela histórica. Se trata, al mismo tiempo, de una reescritura de textos en la que se puede apreciar algo cercano a lo que Jameson denomina "a hidden master narrative", es decir "a sequence of historical events or texts and artifacts ... rewritten in terms of some deeper, underlying, and more 'fundamental' narrative" (Jameson 28).

Pero tal resultado textual no hace más que confirmar, en todo caso, la postura retórica y cultural desde la cual la Avellaneda plantea la estrategia de su novela histórica americana. Y ello significa la novela concebida como viaje redescubridor e interpretativo a las dimensiones de un pasado monumental, operando mediante una laboriosa selección textual de vestigios y fragmentos de una historia encapsulada - a la manera de lo queluego se conceptualizará como "novela arqueológica" - para proceder a integrarlos y reescribirlos en términos de un código determinado, que es, en este caso, el romance histórico. Es así como se puede concluir que en Guatimozín la novelista revela a la historiadora romántica, dotada de una fundamental concepción del historiador como intérprete de los pueblos "mudos", a la manera de Michelet: el poeta-historiador cuya labor puede interpretarse como un descenso a la matriz histórica del pasado de los pueblos; la investigación histórica, por último, como viaje en el tiempo. Pero téngase en cuenta que desde la perspectiva de la Avellaneda autora de Guatimozín y el contexto político-cultural en el que opera, tal esencia del historicismo romántico debe entenderse 
también como un planteamiento disonante, como heterogeneidad discursiva redefinidora de un discurso colonial y como instancia subvertidora del unisonante registro genérico del historicismo literario de su época - del que había estado significativamente ausente el tema de la conquista americana - al tiempo que su novela articula las modalidades textuales que definen la práctica del género histórico en Hispanoamérica.

\section{ObRAS CITADAS}

Adams, Percy G. Travel Literature and the Evolution of the Novel. Lexington: University Press of Kentucky, 1983.

Barthes, Roland. Le degré zéro de l'écriture. [1953] Paris: Editions du Seuil, 1972.

Benítez-Rojo, Antonio. "Nacionalismo y nacionalización en la novela hispanoamericana del siglo XIX." Revista de crítica literaria latinoamericana 38 (1993): 185-93.

Bhabha, Homi. The Location of Culture. London: Routledge, 1994.

Certeau, Michel de. Heterologies: Discourse on the Other. Minneapolis: University of Minnesota Press, 1985.

Cotarelo y Mori, Emilio. La Avellaneda y sus obras. Madrid: Tipografia de Archivos, 1930. Frye, Northrop. The Secular Scripture. Cambridge, MA: Harvard University Press, 1976. Gómez de Avellaneda, Gertrudis. Espatolino. Obras. Tomo V. Madrid: Atlas, 1981. 9-81. Guatimozín. Mary Cruz, ed. La Habana: Letras Cubanas, 1979.

"Mi última excursión por los Pirineos". Obras. Edición Nacional del Centenario.

Tomo VI (Miscelánea). La Habana: Imprenta de Aurelio Miranda, 1914. 7-47. Obra selecta. Mary Cruz, ed. Caracas: Ayacucho, 1990. Sab. Barcelona: Orbis, 1988.

Henríquez Ureña, Pedro. Ensayos en busca de nuestra expresión. Buenos Aires: Raigal, 1952.

Jameson, Fredric. The Political Unconscious. Ithaca: Cornell University Press, 1981.

Jitrik, Noé. Historia e imaginación literaria. Buenos Aires: Biblos, 1995.

Méndez Bejarano, Mario. Tassara: Nueva biografia crítica. Madrid: Imprenta de J. Pérez, 1928.

Molloy, Sylvia. At Face Value: Autobiographical Writing in Spanish America. Cambridge: Cambridge University Press, 1991.

Pratt, Mary Louise. Imperial Eyes: Travel Writing and Transculturation. London: Routledge, 1992.

Rodríguez, Ileana. House/Garden/Nation: Space, Gender, and Ethnicity in Postcolonial Latin American Literatures by Women. Durham: Duke University Press, 1994.

Sebold, Russell P. Bécquer en sus narraciones fantásticas. Madrid: Taurus, 1989. 